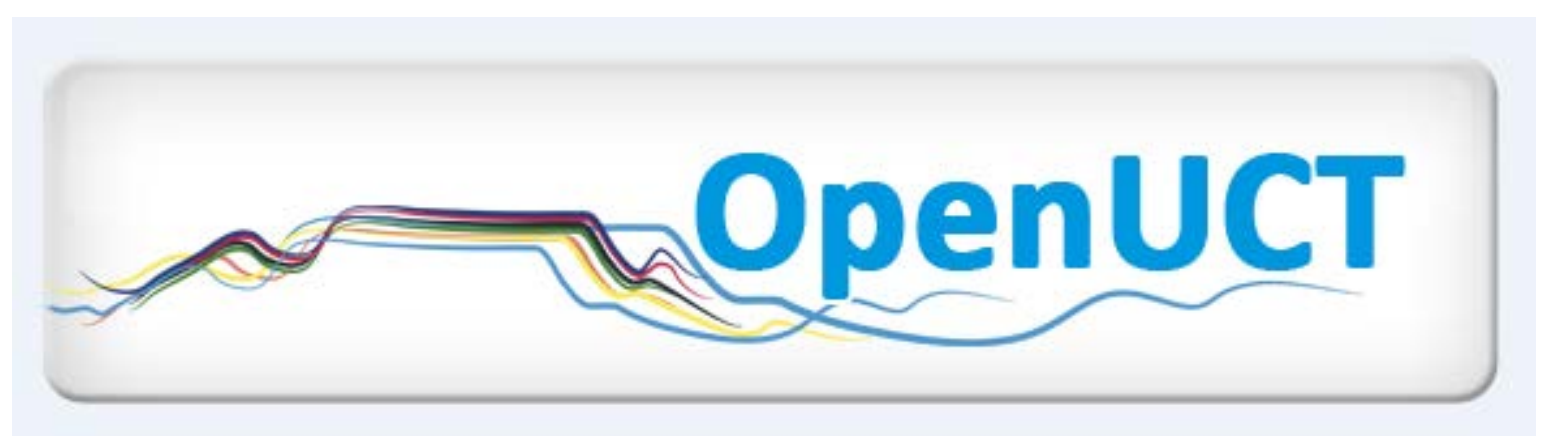

This is the post-print of Shay, S. 2012. Educational development as a field: are we there yet? Higher Education Research \& Development. 31(3): 311-323. DOI: 10.1080/07294360.2011.631520.

It is made available according to the terms of agreement between the author and the journal, and in accordance with UCT's open access policy available:

http://www.openuct.uct.ac.za/sites/default/files/UCTOpenAccessPolicy.pdf, for the purposes of research, teaching and private study. 


\section{Educational development as a field: are we there yet?}

Suellen Shay

Centre for Higher Education Development, University of Cape Town, Cape Town, South Africa

This paper contributes to the critical engagement about educational development and its status as a field. The critique focuses in particular on our knowledge and the nature of our knowledge-building. The paper argues that unless we strengthen our knowledge base we will not emerge as a professional field able to engage rigorously and systematically with the problems of higher education. Drawing on social realist work that builds on the ideas of Basil Bernstein, a framework is offered for conceptualizing knowledge differentiation and the implications of different types of knowledge for knowledge-building. The paper concludes with suggestions on how educational development might strengthen its knowledge-building capacity.

Keywords: educational development; knowledge; professional development

\section{Introduction: making the case for knowledge}

As an emerging field of practice or a profession 'coming of age' (Clegg, 2009a), educational development has been the subject of critical dialogue in recent higher education publications (see, for example, Studies in Higher Education, Special Issue, 344). The term 'educational development', or 'academic development', has different meanings across the globe (Clegg, 2009b). I use it in this paper to encompass a range of development and research practices aimed at the professionalization of teaching and learning in higher education, most commonly associated with various forms of student, staff, curriculum and policy development. One of the aims of this dialogue is to critically examine the knowledge that informs these educational development practices, in particular the theoretical frames of reference and methodological approaches that have shaped what we know and how we come to know what we know (Shay, Ashwin, \& Case, 2009). This paper continues this critical exploration of the status of educational development as a field. The critique is inspired by a paper of Maton's (2008) entitled 'Knowledge-building: How can we create powerful and influential ideas?' where he addresses the conditions for generating powerful explanations that address the pressing problems facing society. This paper focuses on our knowledge and specifically the nature of our knowledge-building.

To focus on knowledge-building in educational development makes certain assumptions: that as a community we are in the knowledge-building business, that knowledge-building in such a community is possible, indeed, that there is such a thing as knowledge. To assume the reality of knowledge, does not deny that is it fallible and value-laden, that it is largely linguistic or that there are different kinds of knowledge. All of these assumptions raise a number of ontological and epistemological debates, which will not be pursued here. The key premise is that the stronger our knowledge foundations - the conceptual or theoretical basis underpinning our practice - the more likely we are to understand and resolve the seemingly intractable problems facing us in higher education. To put it more bluntly, without the strengthening of our knowledge base we will not emerge as a professional field able to engage rigorously and systematically with these problems. Knowledge does matter. This is not a new point. Sociologists of education rooted in social realism have been arguing for some time that knowledge has been rendered virtually invisible in much educational theory and research work (Freebody, Maton, \& Martin, 2008; Maton \& Moore, 2010; Moore, 2007; Muller, 2000; Wheelahan, 2010; Young, 2003). In this paper the critique is simply turned specifically on one branch of education - the field of educational development.

And, indeed, there are stubborn and pressing problems - problems of access and placement, progression and retention as well as concerns about the overall quality of the graduate to contribute to local and global society. In South Africa, Scott (2009a) argues that our higher education system - 14 years post-apartheid - continues to fail the majority of the population. This, he argues, has major implications for social, political and economic development. Scott provides evidence of this failure in undergraduate performance patterns (Scott, Yeld, \& Hendry, 2007): South Africa has a higher education participation rate of $16 \%$ of its $20-24$ age cohort, which is lower than other economically comparable countries. (The average for developed countries is between 60 and $90 \%$.) The real tragedy is exposed, however, when this participation rate is disaggregated by race to reveal a white participation rate of $60 \%$ and a black South African rate of $12 \%$. 
Once students are admitted, the picture does not get better. A cohort study of the 2000 intake (Scott, Yeld, \& Hendry, 2007) showed that after five years only $30 \%$ of the undergraduate intakes have graduated. If optimistic assumptions are made about students transferring elsewhere and some taking longer than five years to graduate, the overall completion rate still stands at no more than $45 \%$ of the cohort. Again when this figure is disaggregated by race, the sobering reality is that under $5 \%$ of black South Africans in the 20-24 age cohort are succeeding in public higher education (Scott, 2009a, 2009b). This is the basis of Scott's claim that our higher education system is failing the majority. It is this failing higher education system that is our field of practice. Scott (2009b) argues that our 'craft knowledge' approaches to solving these problems will not do what is called for is 'systematic knowledge' of teaching and learning theory and practice.

As a member of the educational development community in South Africa for over 20 years, I have been involved, alongside colleagues, in a number of initiatives to strengthen this systematic knowledge that Scott calls for. Against the backdrop of the urgent problems described above, there is a great need and unique opportunity for educational development to offer 'powerful and influential ideas' (Maton, 2008).

This requires, however, that we examine carefully what we have to offer. To this end, in the first part of this paper I review some of the characterizations and critiques of educational development as a field. In the second part, drawing on the work of sociologist of education Basil Bernstein and Bernsteinian scholars, I offer a conceptual framework for thinking about knowledge and knowledge-building. The usefulness of this framework for analyzing knowledge differentiation and the implications for knowledge-building are illustrated through a case study drawn from the South African- Norway Tertiary Education Development (SANTED) Nelson Mandela Metropolitan University project (henceforth referred to as the SANTED project). Finally, I offer some perspectives on how we might strengthen our knowledge-building practices.

\section{Education development: what kind of field?}

Clegg (2009a) proposes that we might think of academic development as a 'region'. This is a term borrowed from Bernstein (2000) to characterize fields that face inwards towards disciplines and outwards towards external fields of practice. Professional fields are 'regions' where disciplinary knowledge is 'recontextualized' to address problems in the field of practice. 'Recontextualization' is a term used by Bernstein to describe a process whereby something (in this case knowledge) is selected, de-contextualized and then placed into a new context. Recontextualization always involves a transformation of the original selection. This 'two-faced' nature of a region has implications for the identity of the inhabitants of these fields. Bernstein characterizes it as a 'projected identity' - an identity that is strongly shaped and regulated by the field of practice. We might think of older regions such as Medicine, Engineering and Law, which Muller (2009) describes as having a strong epistemological base in the discipline and a strong social base in the organization of the profession, resulting in a 'robust professional habitus and identity' (p. 214). He contrasts this with the more diffuse professional identities and more arbitrary knowledge base of other regions such as teaching, social work and clinical psychology and even newer ones such as tourism, business studies and consumer studies.

The notion of educational development as a 'region', with its inward and outward faces and projected identities, requires further exploration. I first focus on the outward face. In the recent literature on the nature and identity of educational development there seems to be a broad consensus that educational development is a distinctive field of practice (Boughey, 2007; Clegg, 2009a, 2009b; Grant et al., 2009; Harland \& Staniforth, 2008; Scott 2009a, 2009b). These practices have been structurally formalized into units established across the higher education sector from the 1970s in the USA, the UK and Australia and from the 1980s in South Africa in response to a rapidly changing higher education system. The shared project is the improvement of the quality and status of teaching in order to improve the quality of students' experience of learning and ultimately the improvement of the quality of the graduate. This field of practice has had a significant influence on the discourse of higher education teaching and both Clegg (2009b) and Scott (2009b) enumerate the many achievements. Land (2004) argues that it is a moral project, a project oriented towards change, towards improvement for the betterment of students. Clegg (2009a) warns that no project, however wellintentioned, can simply claim the moral high ground. 
In attempting to capture something of the nature of this field of practice I draw on Maton's (2008) characterization of intellectual fields. He likens these fields to cosmologies - systems of ideas, practices and beliefs - which can be axiologically or epistemologically charged. In axiologically-charged fields the dominant gravitational pull is around moral, political and social values unlike epistemologically-charged fields where the dominant pull is the explanatory power of knowledge. Maton argues that in any intellectual field both are present, the question is which dominates. An examination of educational development discourses dominated by notions of improvement, change, transformation might point to a strong axiological orientation. This is not a criticism of educational development. The failure of higher education in South Africa described above is morally indefensible and the reform of this system is a political, social and moral project. But what about educational development's epistemological base?

With respect to the inward face of the region towards its disciplinary knowledge, the literature is less confident. There are references to educational development as a 'profession' where the scare quotes might signify ambivalence (Grant et al., 2009). Clegg (2009a), borrowing from Collier (1997), refers to educational development as a 'concrete science' in contrast to an 'abstract science'. Concrete sciences are experiential and their 'truths are ... context related and specific' (p. 411). Harland and Staniforth (2008) are less flattering: pointing to its theoretical fragmentation they describe educational development as a 'family of strangers' (p. 669). With respect to its relationship to its 'parent' disciplines, Haggis (2009) compares the theorization of learning in the disciplines of Sociology and Psychology with the theorization of learning in two of the UK's most prestigious higher education journals. She argues on the basis of her analysis that these higher education journals are one and sometimes two decades behind these two fields that most directly inform theorization in educational development. These accounts point to a somewhat weak knowledge base.

The literature also points to tensions in educational development identities. Given the rise of educational development at the height of South Africa's political transition, Scott (2009b) notes the tension between its activists and those with more academic orientations. Boughey (2007), in a more detailed historical analysis, traces how the role of educational developers has shifted from being agents of progressive equity agenda in the late-1980s and early-1990s to more recently being agents of a more conservative neo-liberal agenda of efficiency through, for example, the implementation of outcomes-based approaches to curriculum. Similarly, Clegg (2009b) notes shifts in educational developers' identities as their relationship to institutional power has allegedly been strengthened. There is much to debate in these various depictions of the educational developer's identity, the way we have positioned ourselves and have been positioned. What it suggests, however, is that the volatility of our contexts compounded by the weakness of our knowledge base may give rise to ambivalent professional identities.

Are we there yet? As a field of practice, there is a good case. As an intellectual or professional field, the case is less convincing. At best we may be characterized as a community of practice (Wenger, 1998), pulling together specialists from areas such as applied language studies, adult education, science education, engineering education and educational technology who care deeply about students and are committed to the improvement of their experience as learners in higher education. More cynically, the fact that we do research at all may say more about the institutions in which we are located and the forms of capital they value than the imperatives of our field of practice.

There are field-like practices emerging, of course. In South Africa, after 30 years of educational development in the trenches - from the classroom to policy work - we now have postgraduate qualifications even up to doctoral level, increased research output, large grant funded projects and journals specializing in higher education. Some have achieved professor status and attempts are being made to acquire academic departmental status for our units. Are we there yet? I would suggest not. These are important and necessary developments but they do not guarantee us the disciplinary or multi-disciplinary foundations required for a region or professional field. We are more akin to Muller's (2009) description of the new professions with diffuse professional identities and an arbitrary knowledge base. 


\section{Accounting for knowledge differentiation: a conceptual framework}

Where do we go from here? The critique requires a conceptual framework for thinking about our knowledge base and how we might strengthen it. Central to this conceptualization is Bernstein's (2000) distinction between knowledge and recontextualized knowledge. We can think of the highly theoretical knowledge produced by physicists and how this physics knowledge gets recontextualized or selected and sequenced into a first-year physics textbook. In other words it becomes educational knowledge. Or, pertinent to our case study below, the practices of the journalist in the field of interviewing, note-taking and report-writing are recontextualized into a course on News Writing. The relevant question for educational development is what kind of knowledges do we draw on and how do these get recontextualized for varied development purposes in our work with staff and students? To fully answer this question would require empirical study into these practices, which is beyond the scope of this paper. What the paper does offer is a framework for conceptualising different knowledge types and their recontextualization process.

For this conceptual framework I draw on research conducted under the auspices of the SANTED project.1 This project was set up to assist the newly established comprehensive universities that resulted from mergers between technical universities, which offered vocational/professional qualifications, and traditional universities, which offered general formative qualifications. This project required a conceptual framework for articulating knowledge differentiation and the recontextualization of knowledge into curricula. I offer the conceptual framework as a tool for critically reflecting on educational development's knowledge base. I then illustrate the value of the conceptual tool by applying it to the analysis of one of the SANTED project curriculum cases - Journalism. The choice of Journalism is somewhat arbitrary and serves merely to illustrate the application of the analytical tool for exposing the opportunities and constraints on knowledge building.

In one of his last intellectual contributions, Bernstein (2000) sets out to elaborate on the forms of knowledge, what he calls 'discourses' - horizontal discourse and vertical discourse. These spatial metaphors are intended to signify something of the way knowledges are organized, how they develop and how they circulate. Horizontal discourse is every day or common sense knowledge. It develops segmentally, in other words, it is strongly tied to context, often without reference to other contexts. It is directed towards specific and immediate goals, for example, figuring out the remote control or the public transport system in a foreign country. Its methods of transmission are often tacit, learned informally, by trial and error. The acquisition of horizontal knowledge is an essential part of how we get on in the world.

The other - vertical discourse - is systematic and principled. The notion of 'verticality' (Muller, 2007) suggests that this knowledge develops by detaching itself from a particular context. It rises above the particular and takes an abstracted, more general form. Its transmission is usually formal and explicit. We recognize this as the stock of academic disciplines. Bernstein makes a further distinction between disciplines that are hierarchically organized, where knowledge grows by developing higher lawlike propositions that account for more and more data (as is typical in many of the natural sciences), in contrast to horizontal knowledge structures where knowledge grows through a series of specialized languages (as is typical in the social sciences and humanities). One can think, for example, of the various 'languages' of education and the heated debates between their 'speakers': the behaviourist, the constructivist, the socio-constructivist and the critical realist. These spatial metaphors were only the beginning of Bernstein's attempt to expose something of the underlying principles that constitute these different knowledges.

With respect to Bernstein's knowledge discourses much of the attention from sociology of education has focused on vertical discourse and distinctions between the hierarchical and horizontal structures. There has been much less interest in horizontal discourse or practical knowledge. If we want, however, to conceptualize knowledge, particularly that of regions, this requires an understanding of practical, context-specific knowledge.

The theorization of practical, context-specific knowledge is Gamble’s (2004) intellectual project. Building on and extending Bernstein's (2000) theorization of knowledge, Gamble (2004, 2009) distinguishes between context-independent general knowledge (Bernstein's vertical discourse) and context-dependent particular 
knowledge (Bernstein's horizontal discourse). The former - general knowledge - can be further divided into both principled and procedural, in other words, 'pure theoretical' knowledge and 'applied theoretical' knowledge. Gamble argues that the same principled/ procedural division can be found in particular knowledge. In other words, practical knowledge can also be principled. Although the cabinet-maker's knowledge is tacit, it is deeply principled. It relies on an understanding or, more precisely, a visualization of the relationships between parts and whole. Gamble (2004) argues that each article produced 'embodies the essential principles of arrangement' (p. 196). Thus there are two kinds of practical knowledge, that of the everyday and that which is principled. This work gives us insight into knowledge-building that emerges from the field of practice often tacit but, as Gamble argues, highly principled, enacted, embodied.

Drawing on Gamble's conceptual distinctions, we devise a knowledge typology that distinguishes between 'conceptual knowledge' and 'procedural knowledge'. For each of these types there is one further distinction between principled and procedural, thus creating a four-part knowledge typology (see Figure 1): conceptual knowledge (pure theory), proceduralized conceptual knowledge (applied theory), procedural knowledge (practice) and principled procedural knowledge (codified practice). Thus, both conceptual and procedural knowledge can be principled, but with an important difference - in principled procedural knowledge the principles emerge from the procedures themselves. They emerge from the codification of practice. In proceduralized conceptual knowledge, the principles emerge from the conceptual domain, from theory. Thus, there is a very firm dividing line between conceptual knowledge and the procedural knowledge. They do not necessarily lead one to the other - procedural knowledge does not lead to conceptual knowledge and conceptual knowledge does not lead to procedural knowledge.

\section{Knowledge Typologies}
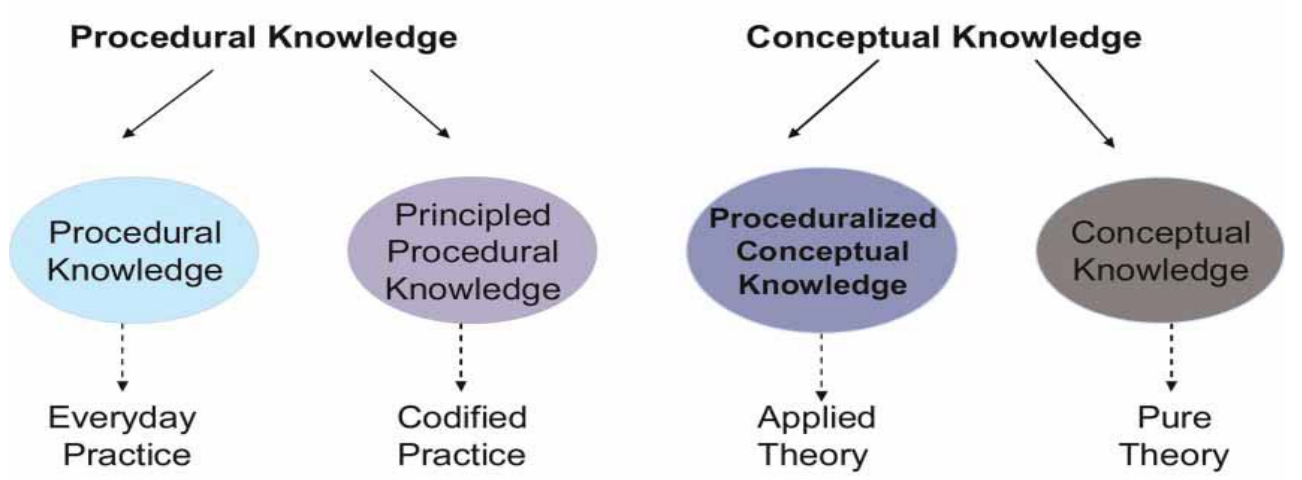

Adapted from Gamble 2009

Figure 1. Knowledge typologies.

With this knowledge typology we can now ask, what kind of knowledge characterizes the field of educational development? From what domain do the principles that inform our practice emerge? Do they come from the domain of practice, in other words, procedural knowledge? Or do they come from the domain of theory, that is, conceptual knowledge? The simple answer is likely to be 'both', but this simplicity hides a complex recontextualization process in which these different kinds of knowledge are drawn on as resources for solving problems in the world of practice. Thus, we need to further develop the conceptual framework from the knowledge typology to how these different knowledges are recontextualized. While the focus of this paper is not on curriculum per se, the SANTED Journalism curriculum case illustrates this recontextualization process and the possibilities for, and constraints on, knowledge-building. 


\section{Conceptualizing knowledge-building: a case from Journalism}

What happens when these different kinds of knowledge are recontextualized for different purposes, in this case study into curriculum? Muller (2009) distinguishes between different curriculum logics, that is, curricula that have conceptual coherence and those that have contextual coherence. Conceptual coherence refers to curricula where the logic of the curriculum comes from the conceptual building blocks of the discipline. The relationship between these concepts will differ across disciplines: for mathematics it may be sequential, for life sciences it may be taxonomic, for history it may discursive. But, irrespective of the relationship between the concepts, the logic of the qualification is a conceptual ladder. For example, in a Sociology course one might see topic headings such as self, identity, roles, socialization, identity change, emotion and social interaction, which cohere around different theoretical perspectives.

Contextual coherence refers to curricula where the logic of the curriculum comes from the external purposes of the curriculum, such as professional and occupational requirements. For example, in a Public Relations module in a Human Resources Management programme one might see topic headings such as marketing, advertising, selling, communications and planning a public relations programme. These topics cohere around the various functions of Public Relations. A module on Learning and Teaching in Higher Education might have headings such as learning, assessment, curriculum design, diversity in the classroom. These topics find their logic in the functions of a tertiary educator.

These logics are better thought of as a continuum, for both are always present. Curricula that cohere around a contextual logic are not devoid of conceptual knowledge and curricula that cohere conceptually are not devoid of contextual concerns. Within a programme we might see a shift in logic across the years of study as is typical of professional programmes where there is strong conceptual coherence at the foundations and more contextual coherence in later years. So both logics can be present at different points in a programme, but the analytical question is which one is the dominant logic? The key premise of this conceptual framework is that depending on the logic of the curriculum - whether it is predominantly conceptual or contextually-oriented, different kinds of knowledge will be recontextualized in different ways.

The analysis of the Journalism diploma and degree curriculum modules revealed a number of curriculum possibilities - what I refer to as curriculum types (see Figure 2). These curriculum types are not exhaustive of the possibilities, they are derived from this curriculum data. The first distinction is between modules that are conceptually oriented and those that are contextually oriented. With respect to those that are contextuallyorientated, there are three possibilities: those with procedural knowledge (C1), principled procedural knowledge (C2) or procedural conceptual knowledge (C3). An example of a C1 type module would be work-based learning modules commonly found in Diplomas where students spend time on work sites. An example of a C2 type module would be modules where students primarily learn a set of procedures as they might in a course called News Writing, such as how to conduct an open-ended interview and how an openended interview for crime reporting differs from one for sports reporting. Students are learning a set of codified practices with no conceptual or theoretical underpinnings. An example of a C3 type module would be modules where the focus is still on media practices but students are required to think conceptually about these practices as they might in a media studies course. With respect to conceptually-orientated modules, there are two possibilities: those with predominantly proceduralized conceptual knowledge (C4) and those with predominantly conceptual knowledge (C5). An example of a C4 type module would be where students are introduced to various theories in order to critique media practices, for example, students are introduced to Marxism in order to assess contemporary culture. An example of a C5 type module would be a fairly exclusive focus on theory, such as a module on cultural studies. Recalling the clear boundary that divides procedural from conceptual knowledge (noted above), similarly there is a clear boundary between those modules that are predominantly C1 and C2 and those that are C3, C4, C5. The latter are constituted by conceptual knowledge, the former are not.

A further analysis was done with regards to the cognitive complexity of the module. The cognitive complexity enabled us to distinguish between, for example, a conceptually oriented module that simply required recall (low complexity) from one where students had to apply the concepts (high complexity). Thus cognitive 
complexity is not codetermined by curriculum type. It is possible to have contextually-oriented curricula - C2 and C3 - at high levels of cognitive demand and, conversely, conceptuallyorientated curricula - C4 and C5 at low levels of cogntive demand. Thus every module was coded for curriculum type (C1-C5) and for cognitive complexity (Low, Medium, High).

\section{Recontextualization of knowledge into curriculum}

\begin{tabular}{|c|c|c|c|c|}
\hline $\begin{array}{c}\text { + Contextual } \\
\text {-conceptual } \\
\text { coherence }\end{array}$ & & & & $\begin{array}{c}\text { +Conceptual } \\
\text {-contextual } \\
\text { Coherence }\end{array}$ \\
\hline C1 & $\mathrm{C} 2$ & C3 & C4 & C5 \\
\hline $\begin{array}{l}\text { Contextual } \\
\text { Coherence } \\
\text { w/ } \\
\text { procedural } \\
\text { knowledge }\end{array}$ & $\begin{array}{c}\text { Contextual } \\
\text { Coherence } \\
\text { w/ } \\
\text { principled } \\
\text { procedural } \\
\text { knowledge }\end{array}$ & $\begin{array}{c}\text { Contextual } \\
\text { Coherence } \\
\text { wl } \\
\text { procedural } \\
\text { conceptual } \\
\text { knowledge }\end{array}$ & $\begin{array}{c}\text { Conceptual } \\
\text { Coherence } \\
\text { w/ } \\
\text { procedural } \\
\text { conceptual } \\
\text { knowledge }\end{array}$ & $\begin{array}{c}\text { Conceptual } \\
\text { Coherence } \\
\text { w/ } \\
\text { conceptual } \\
\text { knowledge }\end{array}$ \\
\hline
\end{tabular}

Figure 2. Curriculum typologies: Recontextualization of knowledge into curriculum

Figure 3 shows the analysis for the Diploma in Journalism and the Degree in Media, Communications and Culture. This analysis enables us to map what knowledge has been selected and how it has been sequenced. What is clear from the Figure is that their core curriculum types are different: for the Diploma it is C2, the Degree is dominated by C2 and C3 with some C4.

One of the aims of the SANTED project is to determine what constitutes a strong Diploma. This analysis points to a Diploma with very little conceptual knowledge. One of the conclusions of the project is that this is problematic: higher educational curriculum must have some proportion of conceptual knowledge (of either the C3 or C4 type). This is consistent with Wheelahan (2010), a vocational and educational training expert, who argues that social access and epistemic access are causally related with the latter being a condition for the former. For this reason 'theoretical knowledge must be at the centre of all educational qualifications, including vocational qualifications’ (p. 145).

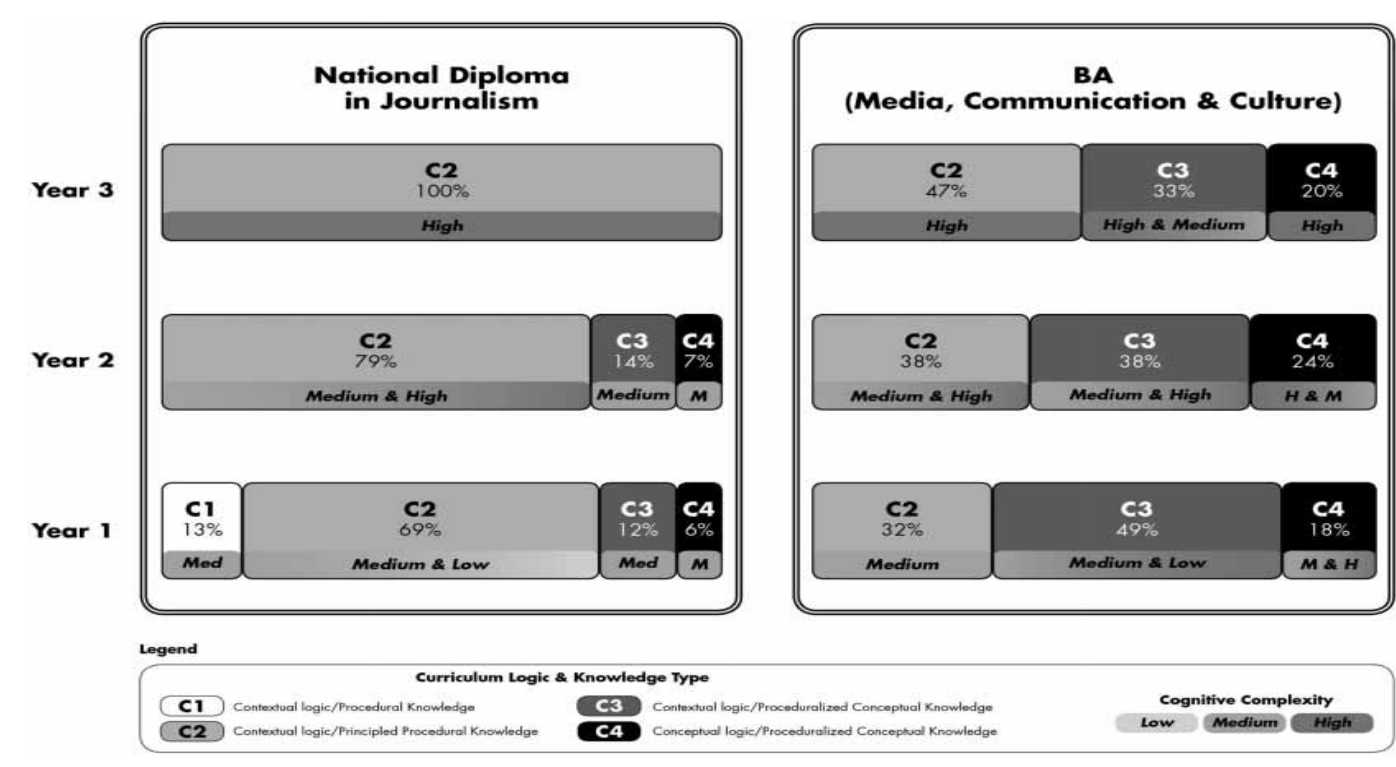

Figure 3. Curriculum coding: Journalism. 
This points to a knowledge-building 'ceiling' on procedural knowledge.While procedural knowledge can be applied in increasingly complex contexts of application, the knowledge remains trapped in its context of application - what Maton (2008) characterizes as high semantic gravity. In procedural conceptual knowledge complexity is achieved by both increasing conceptual complexity as well as more complex contexts of application. Conceptual knowledge is the key ingredient, for it 'lifts meaning out of context through abstracting and condensing the principles underlying that context into a compact language . . . fleshing out concepts through a dialogue with the particularities of that context' (p. 14). The analysis of this Journalism curriculum illustrates the recontextualization of particular knowledges for professional education and the implications of these selections for knowledge-building.

\section{Conclusion: are we there yet?}

With a framework for conceptualizing knowledge and the ways in which it can be recontextualized, I am now in a position to interrogate our status as a field: What is our particular knowledge contribution as a community of educational development? What is the nature of our knowledge-building? There are no definitive answers. If the conceptualization is helpful at all, it is a contribution to the on-going critical engagement within a field that Clegg (2009a) argues is ‘coming of age'.

It is useful to return to Bernstein's distinctions between singulars and regions. Singulars refer to disciplines with either horizontal or hierarchical knowledge structure - where the primary loyalty is towards building disciplinary knowledge. Regions, as noted above, have multiple loyalties. They face both ways - towards the disciplines and towards the world of practice or, as Bernstein (2000) puts it, they 'interface between the field of knowledge production and any field of practice' (p. 9, emphasis added). The case was made at the beginning of the paper that educational development is a clearly established field of practice. The problems endemic of a rapidly transformed higher education system - problems of access, progression, success, quality - are the bread-and-butter business of the educational development community. Ours is unapologetically a contextual logic. But what kind of knowledge do we bring to bear on understanding and solving these complex problems? Strengthening our status as a region necessitates being more clear about the interface between our field of knowledge production and this field of practice.

I noted earlier Scott's (2009b) distinction between 'craft' knowledge and 'systematic' knowledge and his argument that it is the latter that is needed for solving these problems. With our conceptual framework now in place, we can see that craft knowledge is knowledge that is developed through practice. What distinguishes craft from any other practical or procedural knowledge is that it has a principled base but these principles are embodied rather than discursive. In other words, the principles are tacit and can only be explained through reference to a particular. I propose that the field of educational development, in South African anyway, has largely operated from a craft-like knowledge base. It is that kind of deep knowledge that develops out of years of experience of grappling with complex and messy problems in an apprenticeship fashion of learningbydoing, through trial and error but in this case without the benefit of the 'master'. The principles informing this practice are often tacit, for example the much noted but never elaborated 'theories' of change that inform educational development work.

It has to be acknowledged that the kind of expertise in evidence from this craft knowledge has a particular legitimacy. It is recognized as authentic and not least of all because it is deeply rooted in, and arises out of, grappling with particular contextual realities. In South Africa there is a long standing appreciation on the part of highly influential pre- and post-apartheid leaders of the legitimacy of this craft knowledge - from policy makers of the pre-1994 government-in-waiting, to post-apartheid ministers of government, vice chancellors and, not least of all, the academic community.

There are, however, limits to craft knowledge. Gamble (2004) notes that craft apprenticeship as a mode of transmission is no longer viable in contemporary work organizations where change is the norm. The embodied quality of this craft knowledge means that it cannot be easily transmitted - its particularity weighs it down. In attempting to communicate it, to pass it on to others, there is no readily available language. We have to resort 
to story-telling. This may be why many educational development conferences appear to be dominated by the 'show and tell' genre of presentation. There is much to be learned from one another's stories but the learning is constrained by the comparability of contexts: what worked for them does not necessarily work for us. In an attempt to shift from storytelling to something more 'useful' this practical, experiential knowledge is proceduralized. It takes the form of a set of principles or codes for good practice - the embodied principles that form the basis of craft expertise become 'disembodied'. While I have no empirical data for support, my conjecture is that many certificates, diplomas and even some masters offered by educational development units are largely of this 'disembodied' type, stripped of a conceptual base, what we refer to as C2 in the curriculum typology. In these curricula tertiary educators are given and required to apply principles of 'good practice' to solve problems that arise out of their particular contexts, for example, how to design an assessment rubric to ensure reliability, how to facilitate large classes of diversely prepared students. There is certainly a place for this kind of professional development and there is no doubt that it can in some cases lead to improved practice. This is not, however, systemic knowledge. This kind of knowledge has no capacity to explain the problem it is intended to solve. So where does this craft knowledge then leave us?

A number of distinctions have been drawn on in this paper to describe educational development as a field singulars versus regions, systematic versus craft knowledge, epistemological versus axiological.We need to resist the temptation of polarizing these as though one set is less desirable than the other. The issue is how do we solve our stubborn problems and the argument here is that there is a limit to craft knowledge for building a field. The SANTED project provides an illustration of how, in order to solve particular problems faced by comprehensives, we needed to better understand knowledge and curriculum differentiation. We needed a conceptual language that enabled us to move from the particularities of curriculum and pedagogy to the general, what Gamble (2004) refers to as the movement from 'token' to 'type', in this case to knowledge and curriculum types. I would argue a more systematic kind of knowledge has been generated through the use of theory to 'lift' the general principles out of the particular problem in order to return to a reconceptualized problem. The knowledge-building process is thus an iterative movement from the particular to the general and then back to a re-conceptualized particular, from our context-rich understandings and experiences to generalizable principles that can speak across our varied contexts. Harland and Staniforth (2008) are right; our work is theoretically fragmented. Knowledge-building will require working collaboratively and comparatively, building up across our respective languages of description - whether it be critical discourse analysis or activity theory or whether we are using Bourdieu, Bernstein or Vygotsky - to develop more elaborated languages of description. In this way educational development will emerge not only as a recognized field of practice addressing relevant and critical problems in higher education but doing so from a strongly theorized multidisciplinary knowledge base.

\section{Acknowledgements}

I acknowledge the colleagues in the SANTED project for their contribution to the case study used in this paper, the Higher Education Close Up 5 conference organizers - Paul Ashwin, Jenni Case and Sue Clegg - for the invitation to write this paper and to my colleague Laura Czerniewicz for her critical feedback on an earlier draft.

\section{Notes}

1. I acknowledge my colleagues in this research project - Prof. Martin Oosthuizen, Dr. Patsy Paxton and Rene van der Merwe. The use of 'we' in this section of the paper is a reference to our collective work. Further information about this project can be found in Shay, Oosthuizen, Paxton and van der Merwe (2011).

2. Gamble (2009) does not in fact refer to them as knowledge types but rather knowledge-practice relations. I acknowledge the limitations of typologies and future development of this conceptual framework will require exposing the principles that underlie these ‘types' of knowledge. Exposing the underlying principles is consistent with Bernstein's approach to knowledge discourses.

3. Since the case study is presented for illustrative purposes only, I have not included the methodology for how we derived the coding. For a fuller discussion of the SANTED work see Shay, Oosthuizen, Paxton and van der Merwe (2011). 4. This analysis borrows an analytical framework devised for Umalusi - South Africa’s Quality Assurance Body for schooling - reported on in Gamble (2009). 


\section{References}

Bernstein, B. (2000). Pedagogy, symbolic control and identity: Theory, research and critique. (Rev. ed.). Lanham, MD: Rowman \& Littlefield. Boughey, C. (2007). Educational development in South Africa: From social reproduction to capitalist expansion? Higher Education Policy, 20, 5-18.

Clegg, S. (2009a). Forms of knowing and academic development pratice. Studies in Higher Education, 34(4), 403-416.

Clegg, S. (2009b). Histories and institutional change: understanding academic development practices in the global 'north' and 'south'. International Studies in Sociology of Education, 19(1), 53-65.

Collier, A. (1997). Unhewn demonstrations. Radical Philosophy, 81, 22-26.

Freebody, P., Maton, K., \& Martin, J.R. (2008). Talk, text and knowledge in cumulative, integrated learning: A response to ‘intellectual challenge’. Australian Journal of Language and Literacy, 31(2), 188-201.

Gamble, J. (2004). Retrieving the general from the particular: The structure of craft knowledge. In J. Muller, B. Davies, \& A. Morais (Eds.), Reading Bernstein: Researching Bernstein (pp. 189-203). London: Routledge/Falmer.

Gamble, J. (2009). The relation between knowledge and practice in curriculum and assessment. A concept paper commissioned by Umalusi, October 2009.

Grant, B., Lee, A., Clegg, S., Manathunga, C., Barrow, M., Kandlbinder, P., . . ., Hicks, M. (2009). Why history? Why now? Multiple accounts of the emergence of academic development. International Journal for Academic Development, 14(1), 83-86.

Haggis, T. (2009). What have we been thinking of? A critical overview of 40 years of student learning research in higher education. Studies in Higher Education, 34(4), 377-390.

Harland, T., \& Staniforth, D. (2008). A family of strangers: The fragmented nature of academic development. Teaching in Higher Education, 13(6), 669-678.

Land, R. (2004). Educational development: Discourse, identity and practice. Buckingham, UK: Society for the Research into Higher Education and Open University Press.

Maton, K. (2008, December). Knowledge building: How can we create powerful and influential ideas? Paper presented at Disciplinarity, Knowledge and Language: An International Symposium, Australia: University of Sydney.

Maton, K., \& Moore, R. (2010). Introduction: Coalitions of the mind. In K. Maton \& R. Moore (Eds.), Social realism, knowledge and the sociology of education: Coalitions of the mind (pp. 1-13). London: Continuum.

Moore, R. (2007). Going critical: The problem of problematizing knowledge in education studies. Critical Studies in Education, 48(1), 25-41.

Muller, J. (2000). Reclaiming knowledge: Social theory, curriculum and education policy. London: Routledge Falmer. Muller, J. (2007). On splitting hairs: Hierarchy, knowledge and the school curriculum. In F. Christie \& J. Martin (Eds.), Language, knowledge and pedagogy (pp. 65-86). London: Continuum.

Muller, J. (2009). Forms of knowledge and curriculum coherence. Journal of Education and Work, 22(3), $205-226$. Scott, I. (2009a). First-year experience as terrain of failure or platform for development? Critical choices for higher education. In B. Leibowitz, A. van der Merwe, \& S. van Schalkwyk (Eds.), Focus on first-year success: Perspectives emerging from South Africa and beyond (pp. 17-36). llenbosch, South Africa: Sun MeDIA.

Scott, I. (2009b). Academic development in South African higher education. In E. Bitzer (Ed.), Higher education in South Africa: A scholarly look behind the scenes (pp. 21-47). Stellenbosch, South Africa: Sun MeDIA.

Scott, I., Yeld, N., \& Hendry, J. (2007). A case for improving teaching and learning in South African higher education .Higher Education Monitor No. 6. Pretoria: Council on Higher Education.

Shay, S., Ashwin, P., \& Case, J. (2009). Editorial: A critical engagement with research into higher education. Studies in Higher Education, 34(4), 373-375.

Shay, S., Oosthuizen, M., Paxton, P., \& van der Merwe, R. (2011). Towards a principled basis for curriculum differentiation: Lessons from a comprehensive university. In E. Bitzer \& M.E. Botha (Eds.), Curriculum inquiry in South African higher education: Some scholarly affirmations and challenges. Stellenbosch, South Africa: SunMeDIA.

Wenger, E. (1998). Communities of practice: Learning, meaning and identity. Cambridge: Cambridge University Press. Wheelahan, L. (2010). Why knowledge matters in curriculum. London: Routledge.

Young, M. (2003). Curriculum studies and the problem of knowledge: Updating the Enlightenment? Policy Futures in Education, 1(3), 553-564. 